\title{
Renal Failure in Diyala Province
}

\section{Haneen Fathalla Askar $(\mathrm{MBCHB})^{1}$, Ahmed M Athab (MBChB ,FICMS $)^{2}$, Shahab A Shakir (FICMS) ${ }^{3}$ and Nabeel K Mohamad Ali (FICMS) ${ }^{4}$ \\ Abstract}

Background: Renal failure is a worldwide health problem. The incidence and prevalence of renal failure is in constant increase, involving poor outcomes and high costs. The major leading causes of kidney failure are type 2 diabetes and hypertension.

Objective: To study the epidemiology of renal failure in diyala province.

Patients and Methods: A cross sectional study including a review of 284 cases of Renal Failure recorded in Ibn Sina dialysis center in Baqubah teaching hospital in Diyala province for the period from 1st January to the 31st of December of 2018. The collected data was analyzed by using computer, excel and using of SPSS-24. All the variables were analyzed by number, proportion and percentage.

Results: Renal failure prevalence rate was 189.2 PMP and Incidence rate was 112.6 PMP in Diyala province. The Prevalence was in AL-Khalis city 363.15 PMP, Baqubah city 246.9 PMP, Baladroz city 190.9 PMP, AL-Muqdadia city 134.7 PMP and Khanaqin city 100.96 PMP. The mean age of renal failure in Diyala province was $52.9 \pm 15.9$ yrs. Males was about $60.5 \%$ and females was $39.4 \%$. The reasons of Renal failure ratio was diabetes about $33.4 \%$, Hypertension about 23.6\%, Unknown cause about 27.4\%, Glomerilonephritis about 5.3\%, Obstructive nephropathy about $3.16 \%$, Congenital about $2.8 \%$ and others about $4.22 \%$. The major comorbidities in renal failure patient on Hemodialysis was anemia about 48.94\%, Hypertension about $35.2 \%$, Heart failure about $4.57 \%$, Ischemic heart disease about $10.56 \%$ and Cerebrovascular accident about $0.7 \%$. Withdrawal from hemodialysis program in 2018 was $47.3 \%$.

Conclusion:The incidence rate was high and the prevalence rate was low due to low survival.

Keywords: Renal failure, Chronic kidney disease, Hemodialysis, Epidemiology.

Corresponding Author: hanona.modi@gmail.com

Received: $9^{\text {th }}$ April 2019

Accepted: $13^{\text {th }}$ May 2019

DOI:https://doi.org/10.26505/DJM.17024600409

1,2,3 College of Medicine- Diyala University - Diyala -Iraq.

${ }^{4}$ Ibn Sina dialysis center- Baqubah Teaching Hospital- Diyala- Iraq.

\section{Introduction}

Kidney failure, also known as end-stage kidney disease, is a medical problem in

which the kidneys no longer function. The renal failure was subdivided in to acute 
kidney failure AKF ( develop rapidly) and chronic kidney failure CRF ( long term development). Symptoms may include leg swelling, feeling tired, loss of the appetite, vomiting or confusion. Complications of acute disease may include uremia, or volume overload, high blood potassium Complications of chronic disease may includes high blood pressure, heart disease, or anemia [1].

There was no enough information on how to better screen and prevent for the disease, That increasing incidence rate of CRF warrants a need for an epidemiological approach to better demonstration the disease and its prevention. While statistics have been identified concerning world demographics [2].

Epidemiology is the study of the distribution and determinants of healthrelated states or events (including disease), and the application of this study to the control of diseases and other health problems [3].

Renal diseases are estimated in terms of comprehensively renal function glomerular filtration rate (GFR) and the existence of kidneys damage confirmed by either kidney tissues biopsies or another markers of kidney damage. Chronic kidney disease is a common medical condition in which there is a loss of kidney function over time (15). Chronic kidney diseases was associated with increased risks of many co-morbidities; not limited to but including chronic renal failure and cardiovascular disease .CKD is an emergent worldwide public health problem.
The prevalence of end-stage renal disease (ESRD) is increasing in the United States. Chronic kidney disease is increasingly common in developing and developed nations [2].

Chronic renal failure (CRF) is renal failure, which is generally progressive and nonreversible. Presently, the most common cause of $\mathrm{CRF}$ is diabetes related renal disease. Fifty to 60 percent of CRF is of diabetic origin. Frequently, the term end stage renal disease (ESRD) is used for advanced CRF [4].

Awareness of the disorder, however, remains low in many communities and among many physicians. The incidence of end-stage kidney disease has been reduced, where management strategies have been implemented Screening and intervention can prevent chronic kidney disease[5].

This study was aimed to determine the incidence and prevalence of end stage renal diseases on HD program in Diyala province. Determine the age, gender and address distribution, determine the causes of the ESRD and determine the hemodialysis comorbidities in renal failure patients on HD in Diyala province and patient compliance on hemodialysis program in Ibn Sina Dialysis center.

\section{Patients and Methods}

A cross sectional study was conducted in the Ibn Sina center for hemodialysis in Baqubah teaching hospital in Diyala province for the period from 1st January to 31st December 2018. All patients managed and diagnosed as CKD \& on HD in Diyala 
province, including different gender and ages. We reviewed all diagnosed patients and their (medical records) after taking the permission of Ibn Sina doctors and special questionnaire formula used to address the vital issues of the study. Two hundred eighty four patients diagnosed as renal failure and started on hemodialysis in Ibn Sina center for HD, whom were diagnosed by specialists' physicians in this center and or referred from private clinics. Patients were categorized according to questionnaire form containing age, gender, address, causes of renal failure, comorbidities and withdrawal from the HD program.

\section{Statistical analysis}

The collected data was analyzed by using computer, excel and SPSS-24 (Statistical
Packages for Social Sciences- version 24). All the variables were analyzed by number, proportion and percentage.

\section{Results}

During 2018 the Incidence rate of renal failure on hemodialysis was 169 patients which constitute (112.6 person per million of population) and the prevalence rate was 284 patients which constitute (189.2 person per million of population) in Diyala province knowing that total population in Diyala was 1.5 million person [6].

Distribution of patient with renal failure on Hemodialysis according to the gender:In the current study, among (284) renal failure patients, $172(60.5 \%)$ was male and $112(39.4 \%)$ were females, shown in Table [1].

Table (1): Distribution of patient with RF according to the gender

\begin{tabular}{|l||c|c||}
\hline \multicolumn{1}{|c|}{ Gender } & No. & Percent \\
\hline \hline Male & 172 & $60.5 \%$ \\
\hline \hline Female & 112 & $39.4 \%$ \\
\hline \hline Total & 284 & $100 \%$ \\
\hline
\end{tabular}

Distribution of patient with Renal failure $126(44.36 \%)$, from 61-80 years 90 (31.7\%), on HD according to the age:From (284) and $>80$ there is $2(0.7 \%)$ shows in table (2). patients who have renal failure on HD About $50 \%$ of patients were (50-69) year's included this study, the age distribution was age. The mean ages of the renal failure less than 20 years $11(3.8 \%)$, from 21-40 patients on HD in Diyala province was years was 55 (19.36\%), from 41-60 years was $52.9 \pm 15.9$.

Table (2): Distribution of patient with RF according to the Age group

\begin{tabular}{|l|c||c|}
\hline \multicolumn{1}{|c|}{ Age group } & No. & Percent \\
\hline \hline$<20$ yrs & 11 & $3.8 \%$ \\
\hline $21-40$ yrs & 55 & $19.36 \%$ \\
\hline \hline $41-60 \mathrm{yrs}$ & 126 & $44.36 \%$ \\
\hline $61-80 \mathrm{yrs}$ & 90 & $31.7 \%$ \\
\hline$>80$ & 2 & $0.7 \%$ \\
\hline \hline Total & 284 & $100 \%$ \\
\hline
\end{tabular}


Distribution of patient with renal failure on HD according to the address. Among (284) patients renal failure on HD, $143(50.35 \%)$ was from Baqubah city, 69 (24.29\%) was from AL-Khalis city, 31 (10.9) was from Al Muqdadia city, $21(7.39 \%)$ was from Baladroz city and $20(7.04 \%)$ was from
Khanaqin city shown in Table (3). The highest prevalence of $\mathrm{CKD}$ according to population were from Al-Khalis (363.15 PMP) and Baqubah (250.4 PMP). Baladroz, Al Muqdadia and Khanaqin prevalence rate was 190.9, 134.7 and 100.96 PMP respectively shown in Table (4).

Table (3): Distribution of patient with Renal failure on HD according to the address

\begin{tabular}{|l||c|c||}
\hline \multicolumn{1}{|c||}{ Address } & No. & Percent \\
\hline \hline Baqubah & 143 & $50.35 \%$ \\
\hline \hline AL Khalis & 69 & $24.29 \%$ \\
\hline \hline AL Muqdadia & 31 & $10.9 \%$ \\
\hline \hline Baladroz & 21 & $7.39 \%$ \\
\hline \hline Khanaqin & 20 & $7.04 \%$ \\
\hline \hline Total & 284 & $100 \%$ \\
\hline \hline
\end{tabular}

Table (4) : Prevalence in Diyala province sectors (6)

\begin{tabular}{|l||c||c||c|c||c||}
\hline \multicolumn{1}{|c|}{ Sector } & Baqubah & Al Khalis & Muqdadia & Baladroz & Khanaqin \\
\hline \hline Population No. & 571000 & 190000 & 245000 & 110000 & 208000 \\
\hline \hline Patient No. & 143 & 69 & 31 & 21 & 20 \\
\hline \hline Prevalence PMP & 250.4 & 363.15 & 134.7 & 190.9 & 100.96 \\
\hline
\end{tabular}

Distribution of patient with renal failure glomerulonephritis in about 15 (5.3\%), on HD according to the reasons of renal obstructive uropathy in about $9(3.16 \%)$, failure:Among (284) patients renal failure congenital in about 8 (2.8\%), unknown in on $\mathrm{HD}$, the cause of RF was the DM in 95 about $78(27.4 \%)$ and other causes was 12 (33.4\%), hypertension in about $67(23.6 \%)$, (4.22\%) shows in Table (5).

Table (5): Distribution of patient with renal failure on HD according to the reasons

\begin{tabular}{|l||c||c||}
\hline \multicolumn{1}{|c|}{ Causes } & No. & Percent \\
\hline \hline Hypertension & 67 & $23.6 \%$ \\
\hline \hline Diabetes mellitus & 95 & $33.4 \%$ \\
\hline \hline Glomerulo-nephritis & 15 & $5.3 \%$ \\
\hline \hline Obstructive nephropathy & 9 & $3.16 \%$ \\
\hline \hline Congenital & 8 & $2.8 \%$ \\
\hline \hline Unknown & 78 & $27.4 \%$ \\
\hline \hline Others & 12 & $4.22 \%$ \\
\hline \hline Total & 284 & $100 \%$ \\
\hline \hline
\end{tabular}


Distribution of patient with renal failure according to the co-morbidities during hemodialysis:Among (284) patients renal failure on HD anemia in about 139 (48.94\%),
Hypertension in about 100 (35.2\%), HF in about 13 (4.57\%), IHD in about 30 (10.56\%), CVA in about $2(0.7 \%)$ in Table (6).

Table (6): Distribution of patient with RF on HD according to the co-morbidities

\begin{tabular}{|l||c||c|}
\hline \multicolumn{1}{|c|}{ Co-morbidities } & No. & Percentage \\
\hline \hline Anemia & 139 & $48.94 \%$ \\
\hline \hline Hypertension & 100 & $35.2 \%$ \\
\hline \hline Heart failure & 13 & $4.57 \%$ \\
\hline \hline Ischemic heart disease & 30 & $10.56 \%$ \\
\hline \hline Cerebrovascular accident & 2 & $0.7 \%$ \\
\hline
\end{tabular}

\section{Patient compliance on HD program.}

In 2018 from the period of $1^{\text {st }}$ January to $31^{\text {st }}$ December the total center admissions was about 169 Pts about $47.3 \%$ withdrawn from the program and about $8.49 \%$ withdrawn in 2018 from old admissions to HD program before 2018 year.

\section{Discussion}

The prevalence rate (PR) 189.2 PMP and incidence rate (IR) 112.6 P.M.P disagree with study in Aleppo city was (PR) 226 and (IR) 60 [7], also disagree to study in Iran PR was 130.5 and IR was 49.4 [8] . High IR because late diagnosis and poor education and low PR in the study due to high withdrawal ratio and bad thoughts about HD in the Iraqi society. In comparison with other countries shown in Table (7).

Table (7): Incidence and prevalence rate various countries $(9,8,7)$

\begin{tabular}{|l||c||c||}
\hline \multicolumn{1}{|c||}{ Country } & IR(pmp) & PR(pmp) \\
\hline \hline Diyala (2018) & 112.6 & 189.2 \\
Aleppo(2006) & 60 & 226 \\
Iran (2000) & 49.4 & 130.5 \\
Turkey (2011) & 238 & 868 \\
USA(2011) & 362 & 1924 \\
Spin (2011) & 121 & 1075 \\
France (2011) & 149 & 1091 \\
Japan (2011) & 295 & 2309 \\
UK (2011) & 113 & 1924 \\
\hline
\end{tabular}

Renal failure relation to the age distribution, in our study the HD patients ages in Diyala was ranged from 12 yrs. - 90 yrs. disagree with study in Aleppo city who began from 18 yrs age and they have high percent in old ages patients on HD program [7] than Diyala this because high withdrawal rate, high mortality rate, high burden on the family and diagnosed very late. The mean age of patients was $52.9 \pm 15.9$ yrs this agree with study in Kingdom of Saudi in 1999 was 51.3 yrs.[10], disagree with study in US at 2003 [11] Mean 
patient age was 60.9 years higher due to good health education and early detection of the disease in early stage and less withdrawal rate from HD program. Renal failure relation to the gender in our study the male patients percent was $172(60.56 \%)$ and female patients percent was about $112(39.34 \%)$ this ratio is disagree with study done in Aleppo city at 2006 which refer to male ratio was about (49.1\%) and female was (50.9\%) [7], but our result agree with study in Al Sudan country the male was $(71.6 \%)$ and female was $(28.4 \%)$ [12]. The male is more than female because the female is a burden in low socioeconomic state families and low education in our society mostly in female.

Prevalence rate of renal failure on HD there was highest rate 363.15 P.M.P was in alKhalis sector because bad health care, late referral of the early stage CKD and poor health education in that sector than others. The lowest rate 100.96 P.M.P was in Khanaqin sector because of proximity from al Sulimania province and most of this sector was Kurdish nationalism they prefer al Sulimania province because bad security situation in Diyala province at the last years . Baqubah, Baladroz and AL-Muqdadia was 250.4, 190.9 and 134.7 respectively due to the distance from the center, health education and the economic state. There was no other comparative study about the same project.

Distribution of patient with renal failure on HD according to their causes of renal failure in the study was HPT, DM, unknown (lupus nephritis, vasculitis and drugs such as nonsteroidal anti-inflammatory drugs and antibiotics), GN, Obstructive nephropathies (renal stones, ureteric stone and $\mathrm{PPH}$ ), congenital (polycystic kidney disease, cystinosis and alport syndrome) and others (post op, preeclampsia) compared to other studies as in Table (8).

The DM was the highest cause percent in HD patients was about $33.4 \%$ was disagree to other studies in UK (9), Aleppo city in Syria (7), AL Sudan (12) and Gaza (13) ; Was 19, 11.3, 5.9 and $21.6 \%$ respectively, due to late diagnosis, uncontrolled blood sugar, incompliant to treatment and diet, bad management and refusing insulin injections. Shown in Table (8).

The HPT cause percent $23.6 \%$ was agree to study in Gaza $24.3 \%$ [13], but disagree with other studies such as al Sudan 3.8\% [12] and UK 9\% [9] showed in Table (8).

There was high ratio unknown causes patient on HD due to poor patient history of the disease, poor imaging studies diagnosis, late referral, patient family neglection and refusing renal biopsy taking due to weak possibilities to yield the cause. While other studies done which are show great difference in ratio with our study, in UK [9], Aleppo [7], and Gaza (13) was 17\%, $8.7 \%$, and $9.9 \%$ respectively. 
Table (8): Percentage of Renal failure causes in various countries $(7,9,12,13)$

\begin{tabular}{||l||c|c||c|c|c||}
\hline \multicolumn{1}{|c|}{ Causes } & $\begin{array}{c}\text { Diyala\% } \\
2018\end{array}$ & $\begin{array}{c}\text { UK\% } \\
2011\end{array}$ & $\begin{array}{c}\text { Aleppo\% } \\
2006\end{array}$ & $\begin{array}{c}\text { Sudan\% } \\
2005\end{array}$ & $\begin{array}{c}\text { Gaza\% } \\
2016\end{array}$ \\
\hline \hline HPT & 23.6 & 9 & 21.1 & 3.8 & 24.3 \\
\hline \hline DM & 33.4 & 16 & 19.5 & 5.9 & 21.6 \\
\hline \hline GN & 5.3 & 19 & 11.3 & 6.8 & 13.5 \\
\hline \hline Unknown & 27.4 & 17 & 8.7 & 71.2 & 9.9 \\
\hline \hline Obst.uropathy & 2.8 & 10 & 6.2 & 3 & 17.1 \\
\hline \hline Others & 3.16 & 11 & 6.5 & 8.5 & 9.5 \\
\hline \hline
\end{tabular}

Distribution of patient with renal failure according to their co-morbidities during HD was the major co-morbidity was anemia in about (48.94\%) disagree to study in Aleppo city (7) was about (91.8\%) more than our study percent due to Epirax injections use program and monthly $\mathrm{Hb}$ level follow up . HPT was $35.2 \%$ disagree to study in Aleppo city (7) was more about $75.6 \%$. IHD was about $16.56 \%$ agree to study in Aleppo (7) was $15.6 \%$ mostly equal. HF was about $4.57 \%$ but in Aleppo was $11.6 \%$. CVA was about $0.7 \%$ disagrees to study in Aleppo was about $8.4 \%$ [7].

Patient compliance on HD program. There is high withdrawal percent in 2018 about 47.3\% from the new admissions in 2018 year due to high mortality rate, late diagnosis, late referral to nephrologists', have comorbidities and most of them old age poor health education. Disagree to study in Ontario in Grand River H. in Canada was $9.41 \%$ (14) was higher.

\section{Conclusions}

The IR was high and the PR was low due to low survival. The male was more than female patients on HD Program in Diyala province.
The causes of RF pts in Diyala most of them were due to DM and HPT. And there was high percent of unknown causes due to late diagnosis, late referral, bad management on early stage 1, 2 and $3 \mathrm{CKD}$ and insufficient imaging study diagnosis. Highest Prevalence rate in AL-Khalis and Baqubah sector, lowest rate in Khanaqin sector.

\section{Recommendations}

Public health education that can be made through different communication media to inform the whole population about risk factors of $\mathrm{CKD}$ and the management. More awareness of doctors and primary health care centers about CKD and early diagnosis, good treatment, early referral to nephrologist.

\section{References}

[1]NIDDK, 2017. Kidney failure. National Institute of Diabetes and Digestive and Kidney Diseases.

[2]Sanyaolu, A., Okorie, C., Annan, R., Turkey, H., Akhtar, N., Gray, F.,Nwaduwa, I. C. (2018). Epidemiology and management of chronic renal failure: a global public health problem. Biostatistics and Epidemiology International Journal,1(1): pp.11-16. 
[3]Who, 2019. Epidemiology. World Health Organization https://www.who.int/topics/epidemiology/en [4]Mandal A. K. \& Prakash J., 2014. Chronic Renal Failure: Clinical. Textbook of Nephrology, pp. 199-214.

[5] Jha, V., G, G.-G., K, I., S, N., B, P., R, S., CW, Y. (2013). Chronic kidney disease. global dimension and perspectives.

[6]IAU, 2010. Diyala Governerate Profile, IRAQ: Inter-agency Information and Analysis Unit. https://reliefweb.int/sites/reliefweb.int/files/re sources/BCB72FFDD35656D2C1257612003 4F2A1-Full_Report.pdf

[7] Moukeh G. et al., 2009. Epidemiology of Hemodialysis Patients in Aleppo city. Saudi Journal Kidney Disease and Transplantation, 20(1), pp. 140-146.

[8]Haghighi AN, B. B. D. M., 2002. The epidemiology of endstage renal disease in Iran in an international perspective. Nephrology, Dialysis and Transplantation, 17(1), pp. 28-32.

[9] Levy J., Brown E. \& Lawrence A., 2016. Oxford Handbook of Dialysis. 4th ed. Great Clarendon Street, Oxford, OX2 6DP,UK: Oxford University Press.

[10]Mohammad S. J., Geraldine G. D., Ail M. A. \& Fahad A. A., 2001. Caring for hemodialysis patients in Sudia Arabia Past, Present and Future.. Saudi Medical Journal, 22(3), pp. 199-204.

[11] Kimmel P. L., Emont S. \& Mossa A. H., 2003. ESRD patient quality of life: symptoms, spiritual beliefs, psychosocial factors, and ethnicity. American Journal of Kidney Diseases, 42(2), pp. 713-721. [12]El-Amin H. et al., 2007. Hepatitis C virus infection in hemodialysis patients in Sudan: Two centers' report. Saudi Journal of Kidney Diseases and Transplantation, 18(1), pp. 101-106.

[13]Shaban T. B., 2016. Prevalence of anemia among hemodialysis patients treated with recombinant human erythropoietin (rhEPO) in Gaza strip, Gaza : AL Azhar University.

[14]Qazi H., 2018. Factors Associated with Dialysis Withdrawal in Chronic Dialysis Patients, Waterloo, Ontario, Canada: the University of Waterloo. [15]Lerma E. V., Sparks M. A. \& Topi J. M., 2018. Nephrology Secrets. 4th ed. Philadelphia: Elsevier. 